\title{
Investigating the Dreaming Content of Migraineurs
}

\author{
Alireza Ghaffarinejad ${ }^{1}$; Ali Mehdizadeh Zareanari $^{2, *}$; Fatemeh Pouya $^{3}$ \\ ${ }^{1}$ Department of Psychiatry, Kerman University of Medical Sciences, Kerman, IR Iran

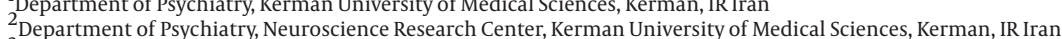 \\ ${ }_{3}^{3}$ Department of Psychiatry, Neuroscience Research Center, Kerman University of Medic
Department of Anatomy, Kerman University of Medical Sciences, Kerman, IR Iran \\ ${ }^{*}$ Corresponding author: Ali Mehdizadeh Zareanari, Department of Psychiatry, Neuroscience Research Center, Kerman University of Medical Sciences, Kerman, IR Iran. \\ E-mail:mehdizadeh93@gmail.com
}

Received: November 17, 2013; Accepted: February 20, 2014

\begin{abstract}
Background: Migraine is common and nocturnal attacks, sometimes, at night make the individual awake. Migraine often induces heavy pressure on the individual and society, and mostly co morbid with psychiatric disorders. Dreaming is a personal and psychological experience that never can be recorded while happening. Different physical-mental situations cause variation in dreaming form. Dreaming content can affect on procedure and features of some psychiatric disorders and it seems some accelerate migraine headaches.

Objectives: Present study investigated the dreaming content of migraineurs.

Patients and Methods: In this cross sectional study, 185 patients with migraine were selected and investigated by available sampling. Migraine diagnosis was based on International Headache Society (HIS) criteria. Dreams were interpreted based on Hall/ Van de Castle, which consisted 11 dreaming content categories. Data was analyzed in SPSS 17 and variables through descriptive statistical tests, analytical ${ }^{2}$, ANOVA and Logistic regression.

Results: Out of 185 patients, 133 were women. In nocturnal migraine, the average number of attacks were more per month $(P=0.006)$. Out of 130 patients, 231 dreams were recorded. Those with nocturnal attacks remembered and recorded their dreams more $(P=0.02)$. Friendliness, sexual and bad fortune contents were more in those with nocturnal attacks $(\mathrm{P}=0.001)$. Sadness, bad fortune, aggression, confusion, $\operatorname{sexual}(\mathrm{P}=0.001)$ and failure accelerated headaches $(\mathrm{P}=0.039)$.

Conclusions: Positive or negative emotions increase headaches. More advanced studies about dreaming contents in different patients and cultures and their comparison with healthy individuals can be helpful in this issue.
\end{abstract}

Keywords: Nocturnal Migraine; Dream; Headache Attack

\section{Background}

Psychiatry is dealing with sleeping, because sleeping disturbances are in all psychiatric disorders. Also sleeping is helpful in the diagnosis of sleeping disorders [1]. Dreaming is a personal and psychological experience that never has been recorded as an event. Sometimes, nightmares are followed by rapid eye movement (REM) inhibitor medicines and then they should be stopped [2]. Dreams have played an important role in psychotherapy, as Freud believed that nightmare is the main road to access unconsciousness [1]. In different physicalmental situations, different dreaming patterns could be possible. Different studies showed that each individual, immediately before waking up, has nightmare. The frequency of dreaming, in both aura and without aura headaches, is the same $[3,4]$. Researchers have shown dreams with the content of aggression, bad fortune, endangering, invasion, and the cause of acceleration in migraine headaches. The largest groups of dreams which peak in migraine are those with the content of danger [5]. Migraine is one of the most common kinds of headaches. Annually, 240 million people, round the world, suffer from headaches [6]. In western countries,
$12 \%$ of adults suffer from headaches and $6 \%$ of them are men [7]. Studies showed that women that suffer from migraine are three times more than men, and the highest rate of migraine prevalence is between 25 - 55 years old [6]. Besides, migraine more occurred among educated and married people [8]. Migraine, also, induces heavy pressure on each individual and every society; based on the report of WHO, the rate of migraine is 19 among all disable disorders [9]. In Iran, generally, migraine prevalence does not exist, but in different groups, wide range of prevalence has been reported. For instance, migraine prevalence among teachers in Shiraz was 10\%, but in Rasht, among high school students, the rate was $86 \%$ $[10,11]$. Migraine is from vascular headaches that often co-morbid with psychiatric disorders such as: anxiety, depression, stress, sleeping syndrome (restlessness leg syndrome) and the risk of suicide which is more common in these patients more than the rest [12-14]. Physical-neurological symptoms are the most significant features of migraine. For instance, in classical migraine (with aura), before any pain, the visual (optical) neurologic symptoms appeared [2]. In general, migraine with-

Copyright (C) 2015, Zahedan University of Medical Sciences. This is an open-access article distributed under the terms of the Creative Commons Attribution-NonCommercial 4.0 International License (http://creativecommons.org/licenses/by-nc/4.0/) which permits copy and redistribute the material just in noncommercial usages, provided the original work is properly cited. 
out aura is more prevalent. Based on the study in Spain, among 155 patients, 99 people had migraine without aura, and 56 people had migraine with aura [3]. Sometimes, GI symptoms, photosensitivity, voice sensitivity and other sensory stimuli, before or after headache attacks appear. Headache attacks may happen at night and even its intensity may be so severe that causes the patient to become awake $[15,16]$.

\section{Objectives}

Based on all these explanations and investigation of previous studies, yet there has not been any comprehensive study with large population on the content of dreaming in patients with nocturnal attacks, yet so the present study investigated the content of dreams in patients with migraine, during 2 years in Kerman.

\section{Patients and Methods}

In this cross sectional study, 185 patients with migraine who referred to outpatient psychiatric clinic in Kerman, they were selected and investigated by available sampling. All of them were aware of this study and were insured about its confidentiality. First, demographic information, such as: age, sex, marital status and education were collected. The patients were carefully examined neurologically and psychiatrically. As soon as main medical disorders such as epilepsy or drug abuse or any other kinds of main psychiatric disorders, except depression, were observed, that patient would be omitted from the study. Type of migraine, the number of attacks, having nocturnal attacks and duration of migraine headache were all investigated and registered for each patient, in his personal file. The information about each patient, just once registered and in later referrals, no more information was considered or added. Types of migraines and kinds of auras were analyzed based on the patient's explanation and diagnoses were based on IHS criteria (at least 5 attacks, headache has at least two of the following characteristics: unilateral location-pulsating quality- moderate to severe pain intensity-aggravation by or causing avoidance of routine physical activity. During headache at least one of the following: nausea and/or vomiting- photophobia and phonophobia not attributed to another disorder). In order to investigate the content of dreams in patients, they were free to think, remember and record the dreams which they had in last 6 months, for illiterate patients, a care giver was responsible to record the dreams. Patients should not have used any specific medicine during this time. Each dream was interpreted based on the Hall/Van de Castle test, which included 11 groups of dreaming contents. Eleven groups were as follow: characters, aggression, friendliness, sexuality, activity, success and failure, misfortune and good fortune, emotions, setting, objects, descriptive elements. Regarding character in dreams, it included individuals who were in the dream or were mentioned. Characters were not considered in general, for example, "anybody, people, or nobody". Furthermore, characters were divided based on the identity (known, or stranger), being alive or not and sex. If a character was mentioned several times in a dream, just once considered and if the patient was in his own dream or referred to, considered separately. Activities in dreams were divided into 6 groups: audio, mental, nonverbal, kinesthetic, visual and verbal. Ambiguous word, like buying, in which there is movement, was omitted. Neither falling was considered as kinesthetic activities, nor, hoping and feeling in mental ones. Other cases related to thinking were in this category. Repeated activity was just once recorded. Activities of different characters were recorded separately. Aggression included: injuring causes death, frightening, chasing, destruction of properties, verbal threatening and hostility. If the character was responsible for violence in a dream, it was considered. Repeated violence was just once recorded. Violent activities were divided into 3 groups, based on the role of the character: being assailant (attacker) or observer of an attack or being attacked. Friendliness consisted: engagement, shaking hands, hugging, kissing, meeting, helping, giving gift, lending, welcoming, greeting, calling, and sympathy. Friendliness could be toward animals even. If friendliness was as a kind of social and specific role, like fire fighters or saving others' properties, all had been recorded. Repeated friendliness activities were just once recorded and separately for each different character. As the character was donator of friendliness or observer or receiver, activities were categorized. Sexual content was: closeness, sexual patting, masturbation, kissing, sexual suggestions, sexual intercourse thought. Sexual activities, even as a job, like prostitute, were also recorded; for different characters separately and if repeated just once. As the dreamer was observer of sexual intercourse or had any role, dreams were categorized. In success and failure category, the individual must do something; otherwise success without any effort was considered as good fortune. Different characters were recorded separately and repetitions were just considered once. Emotional aspect included: sadness, aggression, confusion and happiness. Different events, with different emotions were recorded separately. Emotions of different characters were recorded independently. Several words which conveyed one feeling were in one category. Each feeling (emotion) just once was recorded. Success because of generosity also considered as good fortune. Good/bad fortune was recorded separately for different characters. In order to investigate the dreaming atmosphere (environment) first, the environment was divided into setting and objects. Sometimes, because of short dreaming, the environment was not distinctive. Setting included locations in which the dream had been occurred. If there were any movement in locations, it was recorded. Locations were categorized as: being known, inside, unknown, outside, and strange. Objects were in different forms: recreation, pilgrim, museum, hospital, governmental, church, living and working, body parts, corpse, garment, communicative, edible, weapon, financial, nature, region and trans- 
ferring equipments. Equipments were just once coded and there was no need to be dreamed physically, just being mentioned was enough. About descriptive element, 3 scales were considered: descriptive scale, chronological (time) scale, negative scale. In descriptive scale, concepts which are related to color, size, temperature, age, compression and intensity, speed and direction, and the survey of (beautiful, ugly, right and wrong). In chronological scale, different and necessarily specific periods were considered, such as day, night, and date. In the negative scale, words such as: no, never and seldom were emphasized. In all aforementioned categories, after dreaming, the patient explained any probable headache attacks and if there were any, recorded. After completion and categorization of dreaming codes, data was analyzed in SPSS 17 and the variables were analyzed statistically through descriptive statistical tests, ${ }^{2}$, ANOVA, t-test, and Logistic regression.

\section{Results}

In this study, there were 185 patients who were suffering from migraine; 133 (71.8\%) patients were women and 52 (28.1\%) patients were men. The average age was between $34.6 \pm 11.1$ years, in which the mean of age for women was 34.69 years, a little older than men 34.25 years, although this difference was not statistically significant. Out of 185 patients, 155 (83.7\%) had nocturnal attacks. Among those with nocturnal attacks and those without it, there were not any meaningful differences. Those with nocturnal attacks had suffered from attacks for $7.9 \pm 8.3$ years comparatively those without nocturnal for $9.2 \pm 1.01$ years. This difference between these two groups was not statistically significant.

The average number of migraine attacks per month, for those with nocturnal attacks was $7.8 \pm 5.7$ and that without nocturnal attacks was $4.6 \pm 4.9$. The difference between these 2 groups, based on the average number of migraine attacks per month, was statistically significant $(\mathrm{P}=0.006)$. Seventy two percent of those with the experience of nocturnal attacks were women and the rest were men (27.1\%). Among those with nocturnal attacks and without it, sex did not cause any significant difference. Considering educational level, $14.1 \%$ were illiterate, $15.1 \%$ had primary (elementary) education, 50.8\% high school education and 20\% university degree. There was not a significant difference in level of education between those with migraine attacks and those with nocturnal attacks. Regarding marital status, 48 out of 185 (25.9\%) were single, 131 (70.8\%) were married, 3 (1.6\%) widowed and 3 (1.6\%) divorced. Out of 155 patients with the experience of nocturnal attacks, $24.5 \%$ was single, $1.3 \%$ widows, $72.9 \%$ married and $1.3 \%$ divorced. There were not any meaningful relations based on marital status, between those with nocturnal attacks and those without it. In this study migraine was divided into two groups: with aura and without aura. Out of 155 with the experience of nocturnal attacks, 54 (34.8\%) had migraine with aura and 101 (65.2\%) migraine without aura. There was no sig- nificant relation between the kind of migraine and nocturnal attacks. Also, out of 185 patients with migraine, 130 (70.3\%) of them remembered their dreams, while among them, 114 persons had nocturnal attacks and 16 without any attacks. No significant relation between remembering dreams and nocturnal attacks could be found $(\mathrm{P}=0.02)$.

At investigation of characters in dreams, in all 231 dreams, there were character factors. In all 676 characters which mentioned in dreams of patients with nocturnal attacks, 123 were alive characters, 24 dead, 29 animal, 197 the patient himself, 66 women, 116 known, 80 men and 41 foreigners. Besides, those without nocturnal attacks had 20 characters alive, 1 dead, 3 animals, 28 dreamer, 5 women, 18 known, 14 men, 2 strangers. No significant statistical difference could be found in characters of those with nocturnal attacks or without it. Furthermore, regarding different characters in dream content, in half of dreams with alive characters, $60 \%$ with dead, 56.3\% animals, 52\% dreamers, $50.7 \%$ female, 50\% known, $45.7 \%$ male and $65.1 \%$ strangers, after dreaming the patient experienced headache attacks. Between the characters in dreams and headache attacks after dreaming, no significant relation was found in any of characters.

In 185 dreams out of 231, activities were observed. A survey on these activities showed that 3 (0.89\%) were auditory, 6 (1.79\%) mental, 13 (3.88\%) nonverbal,193 (57.91\%) movement, 28 (8.35\%) visual and 91 (27.16\%) verbal. Investigating these activities in dreams of those with nocturnal and without nocturnal, no significant statistical differences were observed. Also, concerning headache attacks after dreaming, in 33.3\% of dreams with auditory activities, $83.3 \%$ with mental, 61.5\% nonverbal, $42.3 \%$ movement, $60.7 \%$ visual and $47.3 \%$ verbal, headache attacked after dreaming. There were not any significant relations between activities in dreams and headache attacks after them. Out of 71 dreams with the content of aggression, 61 were related to those with nocturnal attacks, 139 out of 160 dreams without aggression content, were for those with nocturnal attacks. In general, no significant relation was found between aggression content and having nocturnal attacks or not. Also, out of 71 aggressive dreams, 42 showed headache after dreaming, and in 160 without aggression, 78 had headache after dreaming, that proves no significant relation between aggression content in dreaming and immediate headache attacks after it.

Regarding friendliness in dreaming, 70 dreams out of 231 had this content that among them, in 26 dreams (37.1\%) the participant was donator, in 4 (5.7\%) observer and in 40 (57.1\%) receiver of kindness. Out of 70 dreams with such content, in 20 (27.5\%) headaches preceded dreaming, in 7 dreams (35\%) the participant was donator, in 2 (10\%) observer and in 11 (55\%) receiver. There were not any significant relations between the role of patient in friendliness and attacks after dreaming. But dreams with the content of friendliness and headache attacks seemed related ( $\mathrm{P}=$ 0.001). Besides, 67 dreams (95.7\%) out of 70 with friendliness content were for those with nocturnal attacks, among 
them in 25 (37.3\%) the patient was donator, in 4 (6\%) observer and in 38 (56.7\%) receiver. But no difference was found, between this group and those without nocturnal, regarding the role of patient in dreams. Generally, there were significant relations between patients with nocturnal and without, in dreams with the content of friendliness and those without $(P=0.001)$ (Table 1$)$. Six dreams $(2.5 \%)$ out of 231 had sexuality content. In 4 dreams (66.7\%), the participant was observer of intercourse; in 2 dreams (33.3\%) participant was recipient. In all 6, after dreaming there was headache attack and the patient had nocturnal attacks. There was no sign of homosexuality.

Out of 33 dreams with the content of success/failure, 30 dreams were for patients with nocturnal attacks, among these dreams, the ones with the content of failure had the highest frequency ( 24 dreams $=80 \%$ ). Also 33 dreams (14.2\%) out of 231 had success/failure content. Among these 33 dreams 18 (45.5\%) headache attacks were after dreaming. No meaningful differences were observed between the content of success/failure and headache attacks after dreaming $(\mathrm{P}=0.03)$, but most of the attacks were after dreams with the content of failure. Emotional content in dreaming included 77 dreams out of 231, which had this content in different forms, which included: 28 dreams (36.3\%) with sadness, 24 (31.2\%) anger, 4 (5.2\%) confusion, $21(27.3 \%)$ happiness. Out of 77 dreams, in 71 , the patient had nocturnal attacks. The highest frequency in content, among patients with nocturnal attacks, was in sadness (24 dreams, 33.8\%) and the lowest frequency in confusion (4 dreams, 5.6\%).

In all emotional categories, the number of those with nocturnal were more than those without, but this difference did not seem statistically significant. Out of 77 with the content of emotion, in 42 dreams (54.5\%) the patient had experienced headache attacks after dreaming, which among them 19 dreams (45.2\%) had sadness content, 24 (31.2\%) anger, 4 (5.2\%) confusion and 21 (27.3\%) happiness. There was significant relation between the kind of emotion in dreams and headache attacks after dreaming ( $\mathrm{P}=$ 0.001). In 91 dreams, out of 231, the content was bad/good fortune (Table 2). Ten dreams (11\%) with good luck content and 81 (89\%) with bad luck. Out of 91 dreams, 77 (84.6\%) were for patients with nocturnal attacks, which consisted 72 dreams (93.5\%) with the content of bad fortune and 5 with good luck. In dreams with the content of bad fortune, nocturnal attacks were more significant $(\mathrm{P}=0.001)$. Out of 91 dreams with the content of good/bad fortune, in 53 (58.2\%) headache attacks were experienced after dreaming, and in all the content was related to bad fortune. Among 38 dreams without any attacks, 28 (73.7\%) were with the content of bad fortune and 10 (26.3\%) good. Significant statistical relations were among the content with good/bad fortune and headache attacks after dreaming $(\mathrm{P}=0.001)$.

A survey on environments showed 309 different forms. Known environments had the highest frequency (129 dreams) and strange ones with the lowest, just in 9 dreams. In 162, the patients had the experience of headache attacks after dreaming, but without any significant relations between this variable and kinds of environment. Also, in all 309 different locations, 267 were for those with nocturnal attacks. In all different environments, the highest frequency was for those with nocturnal attacks rather than those without it, but this difference was not statistically significant. In 41 dreams out of 231, details in environment were mentioned that the total member was 243 different points. Elements (points) related to the nature had the highest frequency ( 43 or $17.7 \%$ ) and the lowest was for details related to entertainers (3 or 1\%). One-hundred eight (44.4\%) were among dreams which followed by headache attacks, but no relation was found between attacks after dreaming and details. Two-hundred fourteen (88.1\%) of those details were in dreams of patients with nocturnal attacks. In general, the frequency of mentioning details in all categories, were more in dreams of patients with nocturnal attacks, but this difference did not seem significant in any of categories.

In investigating descriptive elements, 3 different categories included: descriptive scale, chronological scale and negative. Out of 231 dreams, 40 had these elements that the highest frequency was for the size [11]. In 36 after dreaming was the experience of headache attacks, among the highest frequency related to temperature and size with 7 dreams and the lowest to negative scale with 2 dreams, without any significant relation between the objects in dreams and headache attacks after them. Also, among 60 objects in dreams, 51 were in dreams of patients with nocturnal attacks, in which size had the highest frequency (10 items) and negative scale with the lowest ( 2 items). There were not any meaningful relations between having nocturnal attacks and type of descriptive elements in dreams.

Table 1. Relation Between the Dreams with the Content of Friendliness and Headache Attacks

\begin{tabular}{|c|c|c|c|c|c|c|c|c|}
\hline \multirow[t]{2}{*}{ Variables } & \multicolumn{2}{|c|}{ Migraine With Nocturnal Attacks } & \multirow[t]{2}{*}{ Total } & \multirow[t]{2}{*}{ P-Value } & \multicolumn{2}{|c|}{$\begin{array}{l}\text { Headache Attacks } \\
\text { After Dreaming }\end{array}$} & \multirow[t]{2}{*}{ Total } & \multirow[t]{2}{*}{ P-Value } \\
\hline & Yes & No & & & Yes & No & & \\
\hline Dreams Type & & & & 0.001 & & & & 0.001 \\
\hline With content of friendliness & 67 & 3 & 70 & & 20 & 50 & 70 & \\
\hline Without content of friendliness & 53 & 108 & 161 & & 100 & 61 & 161 & \\
\hline Total & 120 & 111 & 231 & & 120 & 111 & 231 & \\
\hline
\end{tabular}


Ghaffarinejad A et al.

Table 2. Relation Between Content of Dreams (Good/Bad Fortune) With Nocturnal Attacks and Attacks After Dreaming

\begin{tabular}{|c|c|c|c|c|c|c|c|c|}
\hline \multirow[t]{2}{*}{ Variables } & \multicolumn{2}{|c|}{ Migraine With Nocturnal Attacks } & \multirow[t]{2}{*}{ Total } & \multirow[t]{2}{*}{ P-Value } & \multicolumn{2}{|c|}{ Headache Attacks After Dreaming } & \multirow[t]{2}{*}{ Total } & \multirow[t]{2}{*}{ P-Value } \\
\hline & No & Yes & & & No & Yes & & \\
\hline $\begin{array}{l}\text { Content of } \\
\text { Dreams }\end{array}$ & & & & 0.001 & & & & 0.001 \\
\hline Good fortune & 5 & 5 & 10 & & 10 & 0 & 10 & \\
\hline Bad fortune & 9 & 72 & 81 & & 28 & 53 & 81 & \\
\hline Total & 14 & 77 & 91 & & 38 & 53 & 91 & \\
\hline
\end{tabular}

\section{Discussion}

In this study, the average numbers of attacks were more per month. Out of 130 patients, 231 dreams were recorded. Those with nocturnal attacks remembered and recorded their dreams more. Friendliness, sexual and bad fortune contents were more in those with nocturnal attacks. Sadness, bad fortune, aggression, confusion, sexual and failure accelerated headaches.

The content of dreaming (any kinds of emotions, either positive like friendliness or negative like frighten or failure and sexual content) can affect the procedure and specifications of some disorders (for example migraine headache). Migraine is one of the most common kinds of headaches which might co morbid with psychiatric disorders. Recently, different studies deal with disorders co-morbid with migraine, such as: sleeping disorders in patients with migraine, but a few concerned with the content of dreams [16]. The difference between these 2 groups (with nocturnal attacks and those without nocturnal) based on the average number of migraine attacks per month, was statistically significant. Seventy two percent of those with the experience of nocturnal attacks were women and the rest were men (27.1\%). Among those with nocturnal attacks, and without it, sex did not cause any significant difference. So, it seems that nocturnal attacks can be considered as one of the precipitating factors or the more sever the headaches, the more the dreaming can occur. It is mentioned in references, that women got migraine three times more than men [6]. The present study approximates this estimation, so women have migraine 2.5 times more than men. In a survey in Turkey, it was reported that married and educated people had migraine more, which is proved in our study, too. Married people had migraine more than single ones and illiterates had the least frequency [8]. American women had more than 4 attacks per month [17], while in this study, in average, the experience of migraine per month was more than 7 attacks. The average age was between 34.6 \pm 11.1 years, in which the mean of age for women was (34.69), a little older than men (34.25), although this difference was not statistically significant.

Twenty five percent of patients with nocturnal attacks could remember their dreams more than those without it and this difference was significant. Podoll et al. [4] ap- proved this finding in Germany. In a survey [3], 66\% of patients had migraine without aura and the rest with it. In our study, the same result was achieved with $67 \%$. Levitan analyzed 23 dreams of patients with migraine [18]. He categorized them to 6 groups, but in our study, our categorization was to 11, based on Hall/Van de Castle system. In Levitan study, the highest frequency was for frightening content [18], but in our study, among all 11 categories, the highest was related to "character" in dreaming that existed in all 231 dreams.

But this difference seems to be related to different categorization in 2 studies. In our study, among those with migraine, dead characters had the lowest frequency and the patient himself as a character in his dream, had the highest rate. No significant statistical difference could be found in characters of those with nocturnal attacks or without it. Between the characters in dreams, and headache attacks after dreaming, no significant relation was found in any of characters regarding the type of activities, audio had the lowest frequency and kinesthetic the highest, in present study. Investigating these activities in dreams of those with nocturnal and without nocturnal attack, no significant statistical differences were observed. There were not any significant relations between activities in dreams and headache attacks after them. Besides, those were a significant relation between friendliness content and nocturnal attacks in our study.

It seems that any kinds of emotions, either positive like friendliness or negative like frighten or failure accelerate headache attacks. Heather-Greener et al. studies dreams of 37 patients with migraine [5]. As in HeatherGreener et al. 370 dreams from 37 patients were investigated and in our study, 231 dreams out of 130 patients, present study cover variety of characters and as a result more variation in response. So, these differences cause something like aggression. Based on Heather-Greener et al. dreams with the content of aggression, bad fortune and threaten accelerated migraine and even had relation with their appearance [5].

In present study, sexual, failure, bad fortune, sadness, aggression and confusion contents accelerate migraine, but no relation between those headaches and aggression content were found. In our survey, all 
dreams with the content of sexual, co-morbid with headache attacks after dreaming. There has been no evidence to this issue yet in previous studies, but it seems there are relations between sexual emotions and suppressed tendencies in dreams, and nocturnal attacks and headache after dreaming. The content of dreaming can affect the procedure and specifications of some psychiatric disorders. In the study on the content of schizophrenics' dreams, relations between this disorder and dream content were approved [19].

As the study on dreams, related to remembering of them, memory can play effective role, so it is considered as a limitation. Sleeping disorders can be studied with different kinds of headaches, so it is recommended to do this with different headaches. Also, considering larger population and normal participants without any headaches can be useful, comparison between normal participants and those with nocturnal is also recommended. As emotion related to dreams, further studies might be on the patients with complicated grief or considering different cultures.

\section{Acknowledgements}

This research was financially supported by research center of Kerman University of Medical Sciences. The approval number (Ethical) is K|87|12. Executer: Alireza Ghaffarinejad (Code: 86/158).

\section{Authors' Contributions}

Alireza Ghaffarinejad: Study design and revision of the manuscript, Ali Mehdizadeh Zareanari: Data collection and preparation of the manuscript, Fatemeh Pouya: Data Analysis.

\section{Funding/Support}

This research was financially supported by research center of Kerman University of Medical Sciences. The approval number (Ethical) is K|87|12. Executer: Alireza Ghaffarinejad (Code: 86/158).

\section{References}

1. Sadock BJ, Sadock VA . Kaplan and Sadock's synopsis of psychiatry. 9th. edPhiladelphia: Lippincott Williams \& Wilkins; 2007.

2. Sadock BJ, Sadock V, Ruiz P. Comprehensive textbook of psychiatry.Philadelphia: Lippincott Williams \& Wilkins; 2009.

3. Sevillano-Garcia MD, Manso-Calderon R, Cacabelos-Perez P. [Comorbidity in the migraine: depression, anxiety, stress and insomnia]. spanish. Rev Neurol. 2007;45(7):400-5.

4. Podoll K, Töpper R, Robinson D, Sass H. [Recurrent dreams as migraine aura symptoms]. german. Fortschr Neurol Psychiatr. 2000;68(4):145-9.

5. Heather-Greener GQ, Comstock D, Joyce R. An investigation of the manifest dream content associated with migraine headaches: a study of the dreams that precede nocturnal migraines. Psychother Psychosom. 1996;65(4):216-21.

6. Olesen J, Tflet Hansen P, Welch MA. The headaches.Philadelphia: Lippincott Williams \& Wilkins; 2000.

7. Stovner LJ, Andree C. Prevalence of headache in Europe: a review for the Eurolight project. J Headache Pain. 2010;11(4):289-99.

8. Koseoglu E, Nacar M, Talaslioglu A, Cetinkaya F. Epidemiological and clinical characteristics of migraine and tension type headache in 1146 females in Kayseri, Turkey. Cephalalgia. 2003;23(5):381-8.

9. Stovner LJ, Hagen K, Jensen R, Katsarava Z, Lipton R, Scher A et al. The global burden of headache: a documentation of headache prevalence and disability worldwide. Cephalalgia. 2007;27(3):193-210.

10. Ghayeghran AR, Dehnadi Moghadam A, Sedighi Moghadam P Survey of Teachers' Knowledge about Migraine in Rasht in 2005. J Guilan Univ Med Sci. 2007;61(16):51-9.

11. Ayatollahi SMT, Cheraghian B. [An epidemiologic model for risk factors of migraine and tension type headaches among primary schools teachers of Shiraz]. persian. J Kerman Univ Med Sci. 2005;12(2):85-92.

12. Robbins MS, Lipton RB. The epidemiology of primary headache disorders. Semin Neurol. 2010;30(2):107-19.

13. Silberstein SD. Association between restless legs syndrome and migraine. J Neurol Neurosurg Psychiatry. 2010;81(5):473-5.

14. Pompili M, Di Cosimo D, Innamorati M, Lester D, Tatarelli R, Martelletti P. Psychiatric comorbidity in patients with chronic daily headache and migraine: a selective overview including personality traits and suicide risk. J Headache Pain. 2009;10(4):283-90.

15. Cutrer FM, Charles A. The neurogenic basis of migraine. Headache. 2008;48(9):1411-4.

16. Morillo LE. Migraine headache. Am Fam Physician. 2002;65(9):1871-3.

17. Ferrari MD. The economic burden of migraine to society. Pharmacoecon .1998;13(6):667-76.

18. Levitan H. Dreams which culminate in migraine headaches. Psychother Psychosom. 1984;41(4):161-6.

19. Nejad AG, Zadeh BA. Relationship between dream contents and positive/negative symptoms in schizophrenic patients. Neurosciences (Riyadh). 2004;9(4):276-80. 